\title{
Comparison of Questionnaires, Cigarette Butt Counts, and Nicotine Concentration Measurements in Predicting Schoolchildren Nicotine Exposure
}

\author{
C.-C. Chan, Y.-C. Chen, J.-D. Wang
}

National Taiwan University, College of Public Health, Institute of Occupational Medicine and Industrial Hygiene, No. 1, Jen-Ai Road, 1st Section, Taipei, Taiwan, Republic of China

Received: 15 July 1993/Accepted: 20 January 1994

In Taiwan, the import of foreign cigarettes was legalized on January, 1987. The tobacco consumption rate in general population increases from $28.21 \%$ in 1986 to $32.5 \%$ in 1990 ( Taiwan Tobacco \& Wine Monopoly Bureau 1991). In the meantime, the smoking rate among teen-agers also steadily increases. The smoking rate increases from $12.3 \%$ in 1986 to $15.6 \%$ in 1991 among students in junior high schools, and increases from $13.8 \%$ in 1986 to $17.6 \%$ in 1991 among students in high schools ( ROC Department of Health 1991). The successful marketing of imported cigarettes can be best demonstrated by the preference of teenager smokers. The result of a survey conducted in September of 1987, nine months after the cigarettes became legalized, indicates that teenager smokers preferred the imported brands of cigarettes $(82.6 \%)$ to the domestic brands (10.6\%) (The John Tung's Foundation 1987). Considering such a rising trend in cigarette consumption, active as well as passive smoking is expected to be a serious public health problem in Taiwan in the future. In this study, tools of ETS exposure indicators, such as, questionnaire, butt counts and air nicotine concentrations were first evaluated and then applied to estimate schoolchildren's exposure to ETS in Taipei. We will apply the most suitable ETS exposure indicators to a larger population and assess feasible strategies in lowering the public health impact of passive smoking in Taiwan in the future.

\section{MATERIALS AND METHODS}

A stratified sampling method was used in choosing samples. First, we selected three primary schools located in three districts, representing high, middle and low social and economic conditions in Taipei city. Second, we selected three classes, representing 5 to 6 grades, 3 to 4 grades, and 1 to 2 grades in each school. A total of nine classes were chosen. Third, all schoolchildren in these nine classes included as participants. These schoolchildren were asked to fill a questionnaire recalling their time, duration and location of encountering ETS in the previous week. Parents of these children were asked to fill a questionnaire on their social economic status and smoking habits.

Two months later, we randomly selected ten children from homes with smokers and three children from homes with nonsmokers in three classes of one school, identified in the previous questionnaire survey, to participate in a field sampling of estimating personal nicotine exposure. A total of 39 schoolchildren were wearing nicotine passive samplers for two two-day periods, representing children's exposure during weekdays and weekend. Among these 39 children, we randomly selected twelve homes of them to measure the nicotine concentrations in their livingrooms and bedrooms, and to count the cigarette butts. 
All 39 participants were asked to fill time-activity data sheets durin ${ }^{1} \mathrm{~g}$ the sampling period. The data sheets contained information about participant's each hour activity for 24 hours and their chances of encountering ETS. The housing characteristics of 12 homes, including size, building material, and ventilation device, were surveyed and measured by the interviewers. The tobacco butts in participant's living rooms were collected and counted daily.

The method developed by Hammond and Leaderer were adopted to measure ambient nicotine vapor concentrations (Hammond and Leaderer 1987). Briefly, nicotine vapor was collected diffusely onto a sodium bisulfate treated glass fiber filter through a $37-\mathrm{mm}$ filter cassette at a sampling rate of $25 \mathrm{ml} / \mathrm{min}$. In analysis, sodium hydroxide was used to adjust the $\mathrm{pH}$ of the solution. Ammoniated heptane was used to extract nicotine. A small amount of heptane solution was injected into gas chromatography with a nitrogen selective detector (HP 5890). The extraction efficiency was about $64 \%$ and the limit of detection (LOD) was $0.14 \mu \mathrm{g} / \mathrm{m}^{3}$. The relative standard deviation of 12 duplicate samples was $6.8 \pm$ $7.9 \%$ and the blank samples were all below the detection limit. We used one-half of LOD to represent the concentrations of the measurements lower than LOD in our results.

\section{RESULTS AND DISCUSSION}

The response rate of questionnaire survey was $100 \%(419 / 419)$ for children and $90 \%$ (377/419) for parents. A total of 364 children-parent matched questionnaires were obtained in the final analysis after excluding 6 smoking children and 7 questionnaires with inconsistent information on parent's smoking status.

The surveyed parents have relatively high educational backgrounds, About $83.6 \%$ of male parents and $77.9 \%$ of female parents have a degree higher than high schools in this survey. The occupational backgrounds are significantly different between male and female parents. About $61.5 \%$ of male parents have an occupation in business while $51.8 \%$ of female parents housekeepers. The number of people living together in the same home averages at 5 with a maximum of 13 and a minimum of 2 . There are $42.9 \%$ of the 364 homes with at least one smoker. Among them, the maximum number of smokers at home is 4 . The smoking rate is also significantly different between male and female parents. About $50.7 \%$ of the male parents are smokers while only $1.7 \%$ of female parents are smokers. In the weekdays, the male parents who are smokers spent about 4.5 hours per day with their children and smoked about 2.7 cigarettes during that period. In the weekend, the male parents who are smokers spent about 10.6 hours per day with their children and smoked about 5.3 cigarettes during that period.

The male parent's smoking rates are associated with their educational backgrounds. The male parents with a high school degree have the highest smoking rate $(68 \%)$, while those with a college degree have the lowest smoking rate $(42 \%)$. Among the smoking male parents, however, the rates of smoking in front of their children are about the same regardless of educational backgrounds.

At homes, about $42.9 \%$ of children are exposed to ETS. The male parents and grand parents are two main sources of children's ETS exposure at home. Respectively, there are about $37 \%$ of homes having a male parent's source, and $29.6 \%$ male grand parent's. (Table 1) During commuting, the probability of ETS 
exposure for children was about $63.8 \%$ by taking public bus and $20.1 \%$ by using private cars. The cram schools, fast-food stores, and parent's offices are children's three most frequently visited places in the after-school activities. The probability of getting ETS exposure, however, was $10.7 \%$ in cram schools, $52.2 \%$ in parent's offices, and $60 \%$ in fast-food stores. Besides that, children also had $60.8 \%$ of time getting ETS exposure in vedio game stores and $36.4 \%$ in baby-sitters homes. Among the activities over the weekend, children had a probability of $67.4 \%$ getting ETS exposure in cinemas, $64.1 \%$ in vedio game stores, and $50 \%$ in relative's homes. Even in the outdoor suburban areas, the probability was about $32 \%$.

We found that questionnaire is a very convenient way of identifying possible locations, patterns, and durations of children's ETS exposures. The questionnaire identified that educational programs to persuade male parents to avoid smoking in front of their children should target at all educational backgrounds. The timeactivity data indicated that changing life style, such as avoiding smoking by male parents in the livingroom, is a very useful way of lowering ETS for schoolchildren in Taipei.

As expected, the children from smoker's homes were more likely to be exposed to ETS than those from nonsmoker's homes. The mean personal nicotine exposures were $1.30 \mu \mathrm{g} / \mathrm{m}^{3}\left(\mathrm{SD}=0.72 \mu \mathrm{g} / \mathrm{m}^{3}\right.$ ) for children living with smoking parents and $0.24 \mu \mathrm{g} / \mathrm{m}^{3}\left(\mathrm{SD}=0.07 \mu \mathrm{g} / \mathrm{m}^{3}\right)$ for children living with non-smoking parents. There was no significant difference in children's exposure to nicotine between weekdays and weekend. (Table 2)

Table 1. The Probability of Schoolchildren's Exposure to ETS at Homes in Taipei $(\mathrm{N}=364)$

\begin{tabular}{lccc}
\hline ETS source & $\begin{array}{c}\text { No. of children } \\
\text { living wiith }\end{array}$ & $\begin{array}{c}\text { No. of children } \\
\text { exposed to ETS }\end{array}$ & $\begin{array}{c}\text { \% of ETS } \\
\text { exposurre }\end{array}$ \\
\hline father & 346 & 128 & $37 \%$ \\
mother & 333 & 7 & $2 \%$ \\
other relatives & 271 & 38 & $14 \%$ \\
grand mother & 83 & 5 & $6 \%$ \\
grand father & 54 & 16 & $30 \%$ \\
\hline
\end{tabular}

Table 2. Summary of Schoolchildren's Exposure to ETS $\left(\mu \mathrm{g} / \mathrm{m}^{3}\right)$ in Taipei, 1992

\begin{tabular}{lcccc}
\hline Clasification & range & mean(SD) & mediam & sample size \\
\hline Smoker's & & & & \\
Homes: & & & & \\
Weekdays: & ND - 7.80 & $1.31(1.77)$ & 0.72 & 21 \\
weekend: & ND - 6.84 & $1.29(1.76)$ & 0.71 & 21 \\
Whole Week: & ND - 7.80 & $1.30(1.77)$ & 0.72 & 42 \\
Nonsmoker's & & & & \\
Homes: & & & & \\
Weekdays: & ND - 0.95 & $0.27(0.32)$ & 0.07 & 9 \\
weekend: & ND - 0.73 & $0.21(0.27)$ & 0.07 & 9 \\
Whole Week: & ND - 0.95 & $0.24(0.29)$ & 0.07 & 18 \\
\hline
\end{tabular}


Table 3. Indoor Nicotine Concentrations $\left(\mu \mathrm{g} / \mathrm{m}^{3}\right)$ Measured in Schoolchildren's Homes in Taipei, 1992

\begin{tabular}{lccccc}
\hline ETS source & Location & Sample size & range & median & mean(SD) \\
\hline Yes & livingroom & 17 & ND-8.51 & 2.81 & $2.87(2.36)$ \\
& bedroom & 17 & ND-5.58 & 0.48 & $1.11(1.81)$ \\
No & livingroom & 6 & ND-0.67 & 0.07 & $0.24(0.23)$ \\
& bedroom & 6 & <ND & $<$ ND & $<$ ND \\
\hline
\end{tabular}

Table 4. The Characteristics of Smoker's Livingrooms in Taipei, 1992 (N=18)

\begin{tabular}{lcc}
\hline & range & mean(SD) \\
\hline area of opened windows & $0-2.52$ & $0.99(0.87)$ \\
$\left(\mathrm{m}^{2}\right)$ & $20-88$ & $49.78(19.31)$ \\
volume of livingroom $\left(\mathrm{m}^{3}\right)$ & $0-35$ & $14.7(11.6)$ \\
cigarette butt (number) &
\end{tabular}

The nicotine concentrations in homes with smokers were about 10 times higher than those in non-smoker's homes. The mean livingroom nicotine concentrations were $2.87 \mu \mathrm{g} / \mathrm{m}^{3}\left(\mathrm{SD}=2.36 \mu \mathrm{g} / \mathrm{m}^{3}\right)$ for homes with smoking parents and 0.24 $\mu \mathrm{g} / \mathrm{m}^{3}\left(\mathrm{SD}=0.23 \mu \mathrm{g} / \mathrm{m}^{3}\right)$ for homes with non-smoking parents. The mean bedroom nicotine concentrations were $1.11 \mu \mathrm{g} / \mathrm{m}^{3}\left(\mathrm{SD}=1.81 \mu \mathrm{g} / \mathrm{m}^{3}\right)$ for homes with smoking parents and less than $0.14 \mu \mathrm{g} / \mathrm{m}^{3}$ for homes with non-smoking parents (Table 3). For nine smoker's livingrooms, their volumes ranged from 20 to $88 \mathrm{~m}^{3}$, while the areas of windows opened during the sampling periods ranged from 0 to $2.52 \mathrm{~m}^{2}$. The cigarette butt in smoker's livingrooms averaged at about 15 counts in two days (Table 4). During the sampling periods, the participants did not use either air conditioning or fans at homes. We found that nicotine concentrations in livingrooms of homes with smokers were positively correlated with butt counts $(r=0.60)$, but negatively correlated with the areas of opened windows $(r=-0.38)$, respectively. Considering both the nicotine emissions and ventilation conditions, we found the best model to predict nicotine concentrations in the livingrooms is as follows:

$\mathrm{Y}=2.42+0.11 \mathrm{X}-61.94 \mathrm{Z}$

$\mathrm{Y}$ : nicotine concentration in livingroom $\left(\mu \mathrm{g} / \mathrm{m}^{3}\right)$

$X$ : butt count (number of cigarette butt)

$\mathrm{Z}$ : ratio of the areas of opened windows $\left(\mathrm{m}^{2}\right)$ over the volumes of livingroom $\left(\mathrm{m}^{3}\right)$

This model indicated that nicotine concentrations in livingroom increased with the increase in butt counts but decreased with the increase in housing ventilation. We also confirmed that nicotine is a very useful indicator of current ETS exposure. Although our passive samplers can only collect nicotine in vapor phase, we found a significant difference in nicotine concentrations between the exposed and nonexposed homes and persons. The concentrations of nicotine in Taipei were a little lower than the levels of recent studies by Henderson et al.(Henderson et al. 1988), Coulas et al.(Coulas et al. 1990), and Leaderer and Hammond (Leaderer and Hammond 1991) in the U.S. This can partly be attributable to the special characteristics of housing with crowded rooms in subtropical climate in Taiwan, which needs a better housing ventilation and provides a larger absorption surface area of nicotine.

We also found that personal exposure to nicotine was not correlated with either time-activity data or indoor nicotine measurements alone. This finding is in 
agreement with the results reported in previous studies (Coultas et al $1989 \mathrm{~b}$ ). We think this is mainly due to the limitation of time-activity data. It seems not very easy for schoolchildren to document accurately their ETS exposure situations, especially number of smokers around and duration of ETS smell. In contrast, we found that personal exposure can be better predicted by combining indoor nicotine measurements with schoolchildren's time-activity data. We calculated an individual's time-weighted personal nicotine exposures by multiplying measured nicotine concentrations in that individual's livingroom and bedroom by his/her time fraction in each location over two sampling days. The calculated timeweighted exposures were found to be highly correlated with the actually measured personal exposures $(r=0.87)$. The fitted model for regression analysis is as follows:

$Y=0.085+1.431 X$

$\mathrm{Y}$ : the actually measured personal exposures $\left(\mu \mathrm{g} / \mathrm{m}^{3}\right)$.

$\mathrm{X}$ : the calculated time-weighted exposures over two sampling days $\left(\mu \mathrm{g} / \mathrm{m}^{3}\right)$

In conclusion, the impact of ETS on indoor air quality can be estimated by counting cigarette butts and measuring the ventilation conditions in the livingrooms in homes with smokers in Taipei in the spring. However, the personal exposures to ETS can only be estimated by measuring nicotine concentrations either at schoolchildren's breathing zones directly, or in his/her livingrooms and bedrooms indirectly. It is known that ETS exposure can also be estimated by measuring thiocyanate, nicotine, and cotinine in saliva, serum, or urine (NRC 1986). However, these methods are usually more expensive, and require careful timing of specimen collection. Therefore, the methods evaluated in this study, such as cigarette butt counts and questionnaires, are more suitable for application in large-scale epidemiological studies.

\section{REFERENCES}

Coultas DB, Samet JM, McCarthy JF, Spengler JD (1990) Variability of measures of exposure to environmental tobacco smoke in the home. Am Rev Respir Dis 142:602-606 a.

Coultas DB, Peake GT, Samet JM (1989) Questionnaire assessment of lifetime and recent exposure to environmental tobacco smoke. Am J Epidemiol 130:338$347 \mathrm{~b}$.

Hammond SK, Leaderer BP (1987) A diffusion monitor to measure exposure to passive smoking. Environ Sci Technol 21:494-497.

Henderson FW, Reid HF, Morris R (1988) Home air nicotine levels and urinary cotinine excretion in preschool children. Am Rev Respir Dis 140:197-201.

Leaderer BP, Hammond SK (1991) Evaluation of vapor-phase nicotine and respirable suspended particle mass as markers for environmental tobacco smoke. Environ Sci Tecnol 25:770-777.

NRC (1986) National Research Council: Envieronmental Tobacco Smoke, Measureing Exposures and Assessing Health Effects. National Academy Press, Washington, DC.

ROC Department of Health (1991) Special Report on the World No Tobacco Day. Taipei, Taiwan: ROC Department of Health.

Taiwan Tobacco \& Wine Monopoly Bureau (1991) Report on Tabacco and Wine Consumption in Taiwan. Taipei, Taiwan: Taiwan Tobacco \& Wine Monopoly Bureau.

The John Tung's Foundation (1987) Report on Smoking among Youth in Fast Food Restaurants in Taipei. Taipei, Taiwan: The John Tung's Foundation. 